DANIEL KIPER* - LUBLIN

JUSTYNA ŁUKASZEWSKA-HABERKOWA** - KRAKÓW

\title{
LUDWIK BRONARSKI W ŚWIETLE SWOICH DZIENNIKÓW PRZECHOWYWANYCH W ARCHIWUM POLSKIEJ MISJI KATOLICKIEJ W MARLY
}

Sylwetki polskich emigrantów w Szwajcarii, odznaczających się wybitnymi osiągnięciami $\mathrm{w}$ dziedzinach nauki, kultury i sztuki, mimo upływu czasu, są wciąż mało rozpoznane. Głównym powodem tego stanu rzeczy wydaje się być brak źródeł. Co pewien czas jednak udaje się wydobyć z archiwów polskich i zagranicznych rozmaite, niekiedy bezcenne materiały dotyczące życia wybitnych Polaków, nieznane w dotychczasowej w literaturze ${ }^{1}$.

Szwajcaria w pierwszych dekadach XX wieku była miejscem niezbyt licznej emigracji polskiej w porównaniu do innych krajów europejskich, ale o wiele bardziej znaczacej i wpływowej. Obok starej generacji dziewiętnastowiecznych emigrantów politycznych, ich potomków oraz ludności przybywającej do kraju kantonów w celach zarobkowych, tamtejsze ośrodki uniwersytecie przyciągały studentów z Polski. W latach 1880-1918 na uniwersytecie Zurychu oraz Politechnice Federalnej studiowało około 1600 osób z Polski, w Genewie 1200, w Lozannie 620, w Bernie 560, Bazylei 129 i we Fryburgu 602². Polacy mieli swoich przedstawicieli w tamtejszym świecie nauki. Zaliczyć do nich należy przede wszystkim: Józefa Kallenbacha ${ }^{3}$, Stanisława Dobrzyckiego ${ }^{4}$, Tadeusza Estreichera ${ }^{5}$, Sta-

* Daniel Kiper - mgr historii, asystent naukowy w Ośrodku Archiwów Bibliotek i Muzeów Kościelnych, e-mail: kiperus@kul.pl

** Justyna Łukaszewska-Haberkowa - dr hab. historii, adiunkt w Instytucie Kulturoznawstwa Akademii Ignatianumw Krakowie, e-mail: justyna.haberkowa@gmail.com

${ }^{1}$ Wspomnieć tu można choćby listy światowej sławy geografa i geologa prof. Stanisława Lencewicza, przechowywane w Archiwum Polskiej Akademii Nauk, zob. I. Gass, Listy ze Szwajcarii, „Biuletyn Archiwum Polskiej Akademii Nauk”, 55 (2014) s. 155-163.

${ }^{2}$ J. Hulewicz, Les Polonais dans les universités suisses 1864-1918, w: Pologne-Suisses Recueil d'études historiques, Varsovie-Lwów 1938, s. 119, 121, 123, 125. Cyt. Za H. Florkowska-Frančić, Między Lozanną Fryburgiem i Vevey. Z dziejów polskich organizacji w Szwajcarii w latach 19141917, Kraków 1997, s. 57.; por. A[gaton].G[iller], Korespondencya „Ogniwa”, „Ogniwo” nr 37, 25 II 1879, s. 1-2.

${ }^{3}$ Józef Kallenbach (1861-1929) - historyk literatury polskiej okresu romantyzmu. Badacz twórczości Mickiewicza, Słowackiego i Krasińskiego.

${ }^{4}$ Stanisław Dobrzycki (1875-1931) - historyk literatury, slawista, rektor Uniwersytetu Poznańskiego w latach 1924-1925.

${ }^{5}$ Tadeusz Estreicher (1871-1952) - chemik, wykształcony w Uniwersytecie Jagiellońskim, kierownik chemii w Uniwersytecie we Fryburgu. 
nisława Kostaneckiego ${ }^{6}$, Gabriela Narutowicza ${ }^{7}$, Józefa Wierusz-Kowalskiego ${ }^{8}$, Michała Heilperina ${ }^{9}$, czy Władysława Spasowskiego ${ }^{10}$. Szwajcaria była również miejscem sprzyjającym edukacji kobiet. Wykształcenie zdobyły tam m.in. Józefa Joteyko, Wanda Szczawińska, Gabriela Iwanowska i Wanda Korzonówna ${ }^{11}$.

Niniejszy tekst jest próbą spojrzenia na postać polskiego emigranta, muzykologa Ludwika Bronarskiego nie tylko w kontekście jego aktywności zawodowej, ale przede wszystkim życia prywatnego ${ }^{12}$. Podstawowym źródłem, za pomocą którego możemy poznać jego życie i działalność, jest spuścizna rodzinna, znajdująca się w Archiwum Polskiej Misji Katolickiej w Marly. Jedną z najcenniejszych jednostek archiwalnych przechowywanych w tej instytucji są jego Dzienniki, które stanowią niezastąpione źródło biograficzne, a nie zostały dotychczas wykorzystane, ani przez historyków, ani przez przedstawicieli innych dyscyplin naukowych. Bronarski należał do grona osób najbardziej zasłużonych dla rozwoju międzywojennej i powojennej chopinologii nie tylko w Polsce. Jego prace wpisują się także w europejski nurt badań nad twórczością tego kompozytora. Dorobek Bronarskiego na polu historiografii muzyki XX w. nie da się przecenić z uwagi na rozwinięcie teoretycznych kontekstów problemów stylu muzycznego Chopina. Część z tego dorobku stanowiła kontynuację wcześniejszych refleksji naukowych nad morfologią utworów Chopinowskich, ale wiele rozwiązań, wniosła oryginalny wkład do wiedzy na temat harmoniki i stało się punktem wyjścia do dalszych badań nad tymi zagadnieniami ${ }^{13}$.

Ludwik Bronarski urodził się 13 kwietnia 1890 roku we Lwowie, jako syn urzędnika państwowego Juliusza oraz Marii z domu Nikisch. Tam uczęszczał do IV Gimnazjum Klasycznego, które ukończył w 1909 roku. Gruntowne wykształcenie muzyczne zdobył w Uniwersytecie Wiedeńskim, pod okiem Guido Adlera $^{14}$, Richarda Wallaschka ${ }^{15}$ i Hermanna Grädenera ${ }^{16}$. Równolegle przez trzy

${ }^{6}$ Stanisław Kostanecki (1860-1910) - profesor chemii organicznej w Uniwersytecie w Bernie.

${ }^{7}$ Gabriel Narutowicz (1865-1922) - pierwszy prezydent Rzeczypospolitej Polskiej, profesor Politechniki w Zurychu, z wykształcenie inżynier hydrotechnik.

${ }^{8}$ Józef Wierusz-Kowalski (1866-1927) - fizyk i dyplomata. Rektor uniwersytetu we Fryburgu.

${ }^{9}$ Michał Heilperin (1909-?) - ekonomista; pracował w Uniwersytecie w Genewie, Kalifornii i Berkeley.

${ }^{10}$ Władysław Spasowski (1877-1941) - filozof i pedagog. Studiował w Genewie pedagogikę, filozofię i nauki przyrodnicze. W Bernie napisał pracę doktorską pt. Les bases du système de la philosophie morale de Guyau.

${ }^{11}$ M. Micińska, Inteligencja na rozdrożach, Warszawa 2008, s. 165.

${ }^{12}$ Por. M. Gołąb, Ludwik Bronarski (1890-1975), „Rocznik Chopinowski”, 21 (1995) s. 265275 (tam również bibliografia prac uczonego); tenże, Ludwik Bronarski (1890-1975), „Chopin Studies”, 6 (1999) s. 157-167; tenże, Encyklopedia muzyczna PWM. Część biograficzna, t. 1, red. Z. Lissa, Kraków 1979, s. 426-427; M. Panter, Postać profesora Ludwika Bronarskiego, wybitnego znawcy Fryderyka Chopina, w świetle materiałów zgromadzonych w szwajcarskim archiwum Polskiej Misji Katolickiej w Marly, „Polska Misja Katolicka w Szwajcarii. Wiadomości”, nr 453 (czerwiec) 2009, s. 15-18.

${ }^{13}$ Gołąb, Ludwik Bronarski, s. 267.

${ }^{14}$ Guido Adler (1904-1979) - muzykolog i kompozytor, prawnik i publicysta; profesor Uniwersytetu Wiedeńskiego.

${ }^{15}$ Richard Wallaschek (1860-1917) - muzykolog i psycholog, specjalista w dziedzinie muzyki porównawczej oraz badacz muzyki prehistorycznej.

${ }^{16}$ Hermann Grädener (1844-1929) - niemiecki kompozytor, dyrygent i nauczyciel. W latach 1892-1896 pełnił funkcję dyrektora Wiener Singakademie. 
lata studiował naukę gry na fortepianie u Teodora Leszetyckiego ${ }^{17}$. W 1914 roku kontynuował studia muzykologiczne we Fryburgu po kierunkiem Petera Wagne$\mathrm{ra}^{18}$. W tym samym czasie uzupełniał swoją wiedzę $\mathrm{z}$ dziedziny paleografii, nauk pomocniczych historii oraz historii literatury polskiej. Pięć lat później na tamtejszym uniwersytecie obronił pracę doktorską na temat pieśni św. Hildegardy z Bingen (Die Lieder der heiligen Hildegard).Po studiach zdecydował się pozostać na emigracji, gdzie mógł szerzej rozwinąć swoje pasje muzyczne. Spędził tam resztę życia, poszerzając swoje zainteresowania i oddając się twórczości naukowej. Nie znalazł zatrudnienia w Uniwersytecie Fryburskim i zmuszony był imać się rozmaitych zajęć dodatkowych, aby poprawić swoją sytuację materialną. Pracował m.in. w wydawnictwie encyklopedycznym La Pologne 1919-1939 oraz Publication encyclopédique sur la Pologne. Dopiero po wojnie znalazł zatrudnienie jako pedagog. Prowadził klasę fortepianu w Konserwatorium Fryburskim, wykładał teorię muzyki oraz historię muzyki polskiej. W 1948 roku rozpoczął współpracę z Polską Akademią Umiejętności, wchodząc w skład Komisji Muzykologicznej. Należał do kilku instytucji naukowych i stowarzyszeń m.in. Polish Society of Arts and Sciences w Londynie, Association of Polish University Proffesors and Lecturers w Wielkiej Brytanii, Chopin-Gesellschaft w Wiedniu i Związku Kompozytorów Polskich. Czynnie wspierał organizacje i stowarzyszenia polskie na emigracji po roku 1945. Przeszedł na emeryturę w roku 1967, zaprzestając działalności naukowej i pedagogicznej. Zmarł 9 listopada 1975 roku we Fryburgu. Został pochowany na cmentarzu w Bourguillon.

Dzienniki, stanowiące fragment spuścizny rodzinnej zostały przekazane do Misji Katolickiej w Marly przez autora po śmierci jego brata Alfonsa ${ }^{19}$.Trafił tam również księgozbiór oraz archiwum rodzinne głównie dzięki staraniom dominikanina Józefa Bocheńskiego, ówczesnego profesora Uniwersytetu we Fryburgu. $\mathrm{Na}$ jego zawartość składają się m.in. dokumenty, wycinki prasowe, kopie korespondencji wychodzącej i przychodzącej, rachunki, notatki, fotografie, rękopisy wystąpień i wykładów. Niestety, ze względu na zaniedbania i brak nadzoru, a także na skutek wydarzeń losowych (zalanie wodą), część archiwaliów została bezpowrotnie utracona. Ocalałe dokumenty dopiero niedawno zostały uporządkowane i opisane. Nie zatroszczono się jednak o sporządzenie katalogu tej kolekcji. Ucierpiała również bogata biblioteka rodziny Bronarskich, cenna przede wszystkim ze względu na prawie kompletny zbiór książek wydawanych w czasie drugiej wojny światowej i w latach powojennych w tzw. drugim obiegu do roku 1975.

Dziennik prowadził Bronarski prawdopodobnie od chwili, gdy wyjechał ze Lwowa na studia do Wiednia. Niestety, w Archiwum znajduje się tylko jego część. Ogółem jest to 66 jednostek, czyli 61 zeszytów formatu B6 oraz 5 skoroszytów przygotowanych i spiętych z luźnych kartek. Wszystkie zeszyty oraz skoroszyty posiadają kolejną numerację. Pozbawione są sygnatur. Notatki Bronarskiego rozpoczynają się siódmego października 1914 roku, kończą na dacie siedemnastego listopada 1937 roku. Wpisy prowadził w sposób nieregularny, co dwa lub trzy

17 Teodor Leszetycki (1830-1915) - wirtuoz fortepianu, pedagog. Wykształcił muzycznie m.in. Ignacego Paderewskiego, Ignacego Friedmana, Henryka Melcera.

${ }^{18}$ Peter Wagner (1865-1931) - niemiecki muzykolog

${ }^{19}$ Alfons Bronarski (1892-1965) - filolog, pracował jako attaché prasowy Poselstwa Rzeczypospolitej Polskiej w Bernie. Wykładał w uniwersytecie w Neuchâtel i Fryburgu. Publikował m.in. artykuły dotyczące polsko-szwajcarskich stosunków naukowych na przestrzeni wieków. 
dni. Zwykle obok dokładnej daty, zawierają dni tygodnia, podano też miejsce, w którym aktualnie znajdował się autor Dziennika. Dokładny rejestr kolejnych zeszytów przedstawia poniższa tabela:

\begin{tabular}{|c|c|c|}
\hline Numer zeszytu & Od & Do \\
\hline 1 & 2 & 3 \\
\hline 1 & 7 X 1914 (środa)Fryburg & 4 XI 1914 (środa) Fryburg \\
\hline 2 & 5 XI 1914 (czwartek) Fryburg & 20 II 1915 (sobota) Fryburg \\
\hline 3 & 22 II 1914 (poniedziałek) Fryburg & 8 V 1915 (sobota) Fryburg \\
\hline 4 & 9 V 1915 (niedziela) Fryburg & 7 VIII 1915 (sobota) Fryburg \\
\hline 5 & 12 VIII 1915 (niedziela) Neuchatel & 19 XI 1915 (piątek) Fryburg \\
\hline 6 & 20 XI 1915 (niedziela) Fryburg & 11 III 1916 (sobota) Fryburg \\
\hline 7 & 12 III 1916 (niedziela) Fryburg & 12 VI 1916 (poniedziałek) Fryburg \\
\hline 8 & 13 VI 1916 (wtorek) Fryburg & 26 VII 1916 (środa) Fryburg \\
\hline 9 & 27 VII 1916 (czwartek) Marly & 13 XI 1916 (poniedziałek) Fryburg \\
\hline 10 & 14 XI 1916 ( wtorek) Fryburg & 6 I 1917 (sobota) Fryburg \\
\hline 11 & 6 I 1917 (sobota) Fryburg & 20 III 1917 (wtorek) Fryburg \\
\hline 12 & 21 III 1917 (środa) Fryburg & 26 VI 1917 (wtorek) Fryburg \\
\hline 13 & 27 VI 1917 (środa) Fryburg & 14 XI 1917 (środa) Fryburg \\
\hline 14 & 15 XI 1917 (czwartek) Fryburg & 23 III 1918 (sobota) Fryburg \\
\hline 15 & 24 III 1918 (niedziela) Fryburg & $\begin{array}{l}3 \text { VIII } 1918 \text { (sobota) } \\
\text { (w drodze na wakacje) }\end{array}$ \\
\hline 16 & 4 VIII 1918 (niedziela) & 16 I 1919 (czwartek) Fryburg \\
\hline 17 & 17 I 1919 (piątek) Engelberg & 22 III 1919 (sobota) Engelberg \\
\hline 18 & 23 III 1919 (niedziela) Engelberg & 3 VI 1919 (wtorek) Fryburg \\
\hline 19 & 4 VI 1919 (środa) Fryburg & 14 IX 1919 (niedziela) Fryburg \\
\hline 20 & 15 XI 1919 (poniedziałek) Fryburg & 22 VI 1920 (wtorek) Fryburg \\
\hline 21 & 23 VI 1920 (środa) Fryburg & 5 XII 1920 (niedziela) Fryburg \\
\hline 22 & 6 XII 1920 (poniedziałek) Fryburg & 27 VI 1921 (poniedziałek) Fryburg \\
\hline 23 & $\begin{array}{l}28 \text { VI } 1921 \text { (wtorek) } \\
\text { Chatel - ST-Denis }\end{array}$ & 28 XII 1921 (środa) Fryburg \\
\hline 24 & 29 XII 1921 (czwartek) Fryburg & 7 VII 1922 (piątek) Kandersteg \\
\hline 25 & 10 VV 1922 (sobota) Kandersteg & 23 IX 1922 (sobota) \\
\hline 26 & 24 IX 1922 (niedziela) Fryburg & 14 XII 1922 (czwartek) Genewa \\
\hline 27 & 15 XII 1922 (piątek) Fryburg & 16 IX 1923 (niedziela) Fryburg \\
\hline 28 & 17 IX 1923 (poniedziałek) Genewa & 11 XII 1923 (wtorek) Genewa \\
\hline 29 & 13 XII 1923 (czwartek) Genewa & 27 II 1924 (czwartek) Genewa \\
\hline 30 & 28 II 1924 (czwartek) Genewa & 29 V 1924 (czwartek) Genewa \\
\hline 31 & 1 VI 1924 (niedziela) Genewa & 22 VII 1924 (wtorek) Salvan \\
\hline 32 & 22 VII 1924 (wtorek) Salvan & 4 IX 1924 (czwartek) Genewa \\
\hline 33 & 5 IX 1924 (piątek) Genewa & 13 X 1924 (poniedziałek) Genewa \\
\hline 34 & 13 X 1924 (poniedziałek) Genewa & 19 IV 1925 (czwartek) Genewa \\
\hline 35 & 27 IV 1925 (piątek) Genewa & 17 X 1925 (sobota) Genewa \\
\hline 36 & 18 X 1925 (niedziela) Genewa & 28 VII 1926 (środa) Genewa \\
\hline 37 & 29VII 1926 (czwartek) Genewa & 5 II 1927 (piątek) Genewa \\
\hline 38 & 13 IV 1927 (środa) Genewa & 1 XII 1927 (czwartek) Genewa \\
\hline
\end{tabular}




\begin{tabular}{|c|c|c|}
\hline 1 & 2 & 3 \\
\hline 39 & 3 XII 1927 (sobota) Genewa & 2 VIII 1928 (czwartek) Genewa \\
\hline 40 & 3 VIII 1928 (piątek) Adelboden & 9 XI 1928 (piątek) Genewa \\
\hline 41 & 10 XI 1928 (sobota) Genewa & 1 I 1929 (wtorek) Genewa \\
\hline 42 & 2 I 1929 (środa) Genewa & 26 IV 1929 (piątek) Genewa \\
\hline 43 & 27 IV 1929 (sobota) Berno & 22 VII 1929 (?) Poznań \\
\hline 44 & 3 IX 1929 (wtorek) Genewa & 6 V 1930 (wtorek) Genewa \\
\hline 45 & 23V 1930 (środa) Genewa & 19 X 1930 (niedziela) Genewa \\
\hline 46 & 20 X 1930 (poniedziałek) & 22 VII 1931 (środa) \\
\hline 47 & $\begin{array}{l}24 \text { VII } 1931 \text { (czwartek) } \\
\text { Interlaken/ Wengen }\end{array}$ & 25 IX 1931 (piątek) Berno \\
\hline 48 & 25 IX 1931 (piątek) Berno & 6 XII 1931 (niedziela) Genewa \\
\hline 49 & 7 XII 1931 (poniedziałek) Genewa & 30 II 1932 (środa) Genewa \\
\hline 50 & 2 IV 1932 (sobota) Genewa & 14 IX 1932 (czwartek) Genewa \\
\hline 51 & 15 IX 1932 (czwartek) Genewa & 15 IV 1933 (sobota) Genewa \\
\hline 52 & 16 IV 1932 (niedziela) Genewa & 17 VIII 1933 (czwartek) \\
\hline 53 & 18 VIII 1933 (piątek) Plürren & 22 X 1933 (niedziela) Genewa \\
\hline 54 & 29 X 1933 (niedziela) Genewa & 19 VII 1934 (piątek) Genewa \\
\hline 55 & 21 VII 1934 (sobota) Caux & 20 IX 1934 (czwartek) Genewa \\
\hline 56 & 21 IX 1934 (piątek) Genewa & 1 III 1935 (piątek) Fryburg \\
\hline 57 & 2 III 1935 (sobota) Fryburg & 5 VII 1935 (piątek) Fryburg \\
\hline 58 & 6 VII 1935 (sobota) & 1 X 1935 (piątek) \\
\hline 59 & 12 X 1935 (sobota) Fryburg & 19 I 1936 (niedziela) \\
\hline 60 & 24 I 1936 (piątek) Fryburg & 29 IV 1936 (środa) \\
\hline 61 & 29 IV 1936 (środa) & 5 VI 1936 (piątek) \\
\hline 62 & 6 VI 1936 (sobota) & 13 X 1936 (wtorek) \\
\hline 63 & 14 X 1936 (środa) Fryburg & 6 I 1937 (środa) \\
\hline 64 & 7 I 1937 (środa) Fryburg & 14 V 1937 (piątek) \\
\hline 65 & 14 V 1937 (piątek) Fryburg & 17 XI 1937 (środa) \\
\hline
\end{tabular}

Wypowiedzi autora Dzienników charakteryzują się różnymi formami narracji, od lapidarnych opisów, luźnych komentarzy, po bardziej szczegółowe opisy osób, a także głębsze przemyślenia. Doceniał życzliwość kraju, w którym zamieszkał i spędził większość swego życia. Szwajcaria istniała w jego refleksji jako miejsce dobrobytu i pożytecznych rozwiązań społeczno-gospodarczych. Analizował cechy narodowe Szwajcarów siłą rzeczy konfrontując je ze swoją polskością. Doskwierał mu jednak brak zmysłu kulturalnego. We Fryburgu czuł się pod tym względem komfortowo, jednak wrażenia z Berna były mniej entuzjastyczne. Oceniając architekturę tego miasta, które odwiedził z okazji wystawy poświęconej kulturze Szwajcarii, napisał:

Ogólne wrażenie jej [mowa o wystawie] b[ardzo] dodatnie, nawet imponujące [...] budynki w jakimś rokoko; były nawet $\mathrm{b}$ [ardzo] ładne, gdyby były w tem więcej smaku. Ale to jest właśnie, czego - jak zauważyłem - Szwajcarom brak. Nie mają dobrego smaku, szlachetnej prostoty, wykwintnej skromności; 
gdy opuszczą trzeźwość handlowców i kupców to wpadają w gust bankierowsko-dorobkiewiczowski. ${ }^{20}$

W czasie wojny interesował się losem Polski czerpiąc informacje o zmaganiach militarnych z dziennika „La Liberté”. Jego osobiste kontakty z Ignacym Paderewskim oraz, mieszkającym w Genewie Władysławem Mickiewiczem, owocowały udziałem w licznych wydarzeniach kulturalnych organizowanych przez polską emigrację w Szwajcarii. Przyłączył się do manifestacji narodowej podczas pogrzebu Henryka Sienkiewicza w Vevey, którego przebieg opisał w następujący sposób:

My Fryburżanie zajeliśmy najbliższe za tem ławki. [...] Zaczęło się nużące i denerwujące wyczekiwanie, publiczność niespokojna podniecona jak zwykle po polsku. Trochę zbyt swobodnie po salonowemu się zachowująca. Na chórze śpiewacy z organami próbę robili, co nieprzyjemne było, bo osłabiło następne wrażenie. [...] $\mathrm{Na}$ środku kościoła zawieszały się czarne festony i duży herb Polski (orzeł, Pogoń i Anioł). Zresztą nawet okna nie były kirem przesłonięte. Od rana już trumnę złożono przed wielkim ołtarzem, wyniesioną z krypty, dokąd ją potem wieczorem złożyć miano. [...] Publiczności zebrało się b[ardzo] wiele; takiej elegancyi i tyle pięknych twarzy nie widziałem długo jak jestem w Szwajcaryi. [...] Byli też internowani wojskowi. [...] parę minut przed jedenastą klękli przy trumnie pani Sienkiewiczowa z córką i synem, wydziałem ich tylko z tyłu; po nabożeń[stwie] zdaje mi się że widziałem panią S[ienkiewiczową] dokładnie, dość korpulentna; w cwikierze, energicznie wyglądała. Zrobiła się poważna cisza; na organach dał się słyszeć marsz żałobny Szopena (przypuszczam że Opieński grał); po chwili pierwsza zwrotka „Bogurodzicy” a capella unisono) szkoda, że tylko jedną zwrotkę śpiewano, bo dobrze brzmiało i b[ardzo] wzruszające sprawiało wrażenie. [...] Po naboż[eństwie] jeszcze na organach cały jakiś długi, nieładny marsz pogrzebowy dał się słyszeć, a potem zakończono „Boże coś Polskę” dwiema zwrotkami, jak to zwykle u nas, mało kto śpiewał. [...] Naturalnie byłoby tych wieńców nierównie więcej, gdyby nie wojna i nie to, że rodzina prosiła, by zam[iast] kwiatów składać datki na kom[itet] gener[alny $]^{21}$.

Bronarski skoncentrowany był niemal wyłącznie na zewnętrznej oprawie rytuału pogrzebowego, co może świadczyć o tym, że nie czuł z ojczyzną swych przodków szczególnej więzi emocjonalnej. Nie silił się zupełnie na oddanie wzniosłego i patriotycznego charakteru uroczystości żałobnej; wynikało to nie tyle z jego charakteru, co raczej z próby pozbycia się obciążeń związanych z narodową martyrologią.

Z Dzienników wynika, że Bronarski był znany w sferach profesorskich. Wielokrotnie przebywał w towarzystwie autorytetów, opisując dokładnie rozmowy i odczucia, jakie towarzyszyły jego pierwszym spotkaniom m.in. z Wagnerem czy Adlerem oraz seminaria podczas pisania pracy doktorskiej. Notował regularne spotkania z Paderewskim, którego darzył szczególnym szacunkiem, ale bez nadmiernej czołobitności, na co miała wpływ pewna z nim zażyłość. Bronarski relacjonował, przytaczał zasłyszane wiadomości, streszczał bądź cytował wypowiedzi osób z którymi się spotykał.

\footnotetext{
${ }^{20}$ Zeszyt $\mathrm{nr} 48$.

${ }^{21}$ Zeszyt nr 10, k.4-5.
} 
Zapiski Bronarskiego dają obraz skromnego życia polskiej inteligencji na obczyźnie, zmuszonej do wykonywania doraźnych prac zarobkowych, aby się utrzymać na godnym poziomie. Aspekt dotyczący jego spraw codziennych wyraźnie wybijał się ponad zagadnienia, w których poruszał działalność naukowo-badawczą. Skrupulatnie opisywał nabyte drobiazgi: chusteczki do nosa, wstążkę do kapelusza, wydatki na podzelowanie butów, czy na przenicowanie palta. Pozwala to wniknąć w trudne zmagania z prozą życia codziennego, poznać radości i smutki, jakie ze sobą niosło. Sytuacja materialna Bronarskich unormowała się dopiero po wojnie, gdy ojciec Ludwika sprzedał willę we Lwowie, z której fundusze pozwoliły na zakupienie niewielkiego mieszkania w Genewie, przy rue des Vollandes 13.

W Dziennikach uderza nas jeden aspekt osobowościowy Bronarskiego, który zasługuje na uwagę, gdyż odnosi się do światopoglądu ich autora i miał wpływ na jego odbiór rzeczywistości. Był człowiekiem religijnym i przywiązanym do Kościoła katolickiego. Religijność Bronarskiego nie ograniczała się jednak wyłącznie do przestrzegania zewnętrznych form pobożności, jak regularne uczestnictwo w mszach i przyjmowanie sakramentów. Często oddawał się czytaniu Biblii oraz książek religijnych, a także encyklik papieskich. Komentował w Dziennikach wysłuchane kazania, dzielił się refleksjami na temat przeczytanych książek, nierzadko cytował ich treść. W latach 30. minionego wieku był członkiem Towarzystwa św. Wincentego á Paulo. Przywiązanie do religii chrześcijańskiej i wynikający z tego głęboki konserwatyzm, ujawniały się w Bronarskim nawet podczas ocen awangardowej - jak na ówczesną epokę - muzyki. Cytowany niżej fragment, opisujący wrażenia po koncercie, najlepiej oddaje ten światopogląd:

Całkiem inny wieczór, przynajmniej w części: po Kozakach i ich dzikiej, swobodnej pieśni o wschodnim charakterze, wyrafinowana muzyka przedstawiciela zachodnioeuropejskiej kultury muz[ycznej]. Co prawda po Debussym przyszedł Strawiński, który w swym „Sacre du printemps" ma też dzikie, azjatyckie pomysły. W ogóle ciężki wieczór był zniesienia. Przede wszystkiem rozczarowanie: „Martyr de St. Sébastien”, to nie „oratorium”, lecz szereg wkładek muzycznych do dramatu d'Anunnzia. Dramat dla katolika przykry, bluźnierczy nawet przez mieszanie pojęć pogańskich z najświętszymi dla chrześcijanina [...] Jeżeli Debussy nie smakował, to Strawiński był dla mnie wprost niestrawny! Sam program, który St[rawiński] dał dla swego baletu dziwi [...] co to ma być? Zamiast żeby po prostu przedstawiał budzenie się wiosny, tańce na jej cześć, radość ludzi prymitywnych, nastrój epoki dawnej, pełen czaru i poezji itp. to on się bawi w jakąś metafizykę, w jakiś mistycyzm [... $]^{22}$

Z pewnością Dzienniki pozwalają lepiej poznać postać Bronarskiego, uzupełniają jego portret o istotne fakty biograficzne. Możemy na ich podstawie odtworzyć zapis codzienności wraz z całym spektrum osób, które przewinęły się przez jego życie. Dzienniki wnoszą ciekawe informacje dla badaczy realiów polskiej emigracji w Szwajcarii. Jest sprawą dyskusyjną, do jakiego stopnia można je traktować jako świadectwo epoki. Z pewnością sam autor nie miał na celu opisania wielowymiarowej panoramy współczesności. Bardziej koncentrował się na własnych odczuciach, przemyśleniach i problemach życiowych. Ten ludzki wymiar dyktujący charakter, notowanych na gorąco uwag, pozwala odtworzyć i w szczegółach prześledzić tok jego rozumowania. Wyłania się z nich wielowymiarowa osobowość człowieka, muzykologa, Polaka i emigranta.

słowa kluczowe: Polska Misja Katolicka, Szwajcaria, Marly, Ludwik Bronarski, Fryderyk Chopin

\footnotetext{
${ }^{22}$ Zeszyt nr 29, k. 2.
} 


\section{BIBLIOGRAFIA}

Florkowska-Frančić H., Między Lozanną Fryburgiem i Vevey. Z dziejów polskich organizacji w Szwajcarii w latach 1914-1917, Kraków 1997, s. 57.

Gass I., Listy ze Szwajcarii, „Biuletyn Archiwum Polskiej Akademii Nauk”, nr 55 (2014), s. $155-163$.

Giller A, Korespondencya „Ogniwa”, „Ogniwo” nr 37, 25 II 1879, s. 1-2.

Gołąb M., Ludwik Bronarski (1890-1975), „Rocznik Chopinowski”, 21 (1995) s. 265275.

Gołąb M., Ludwik Bronarski (1890-1975), „Chopin Studies”, 6 (1999) s. 157-167.

Panter M., Postać profesora Ludwika Bronarskiego, wybitnego znawcy Fryderyka Chopina, w świetle materiałów zgromadzonych w szwajcarskim archiwum Polskiej Misji Katolickiej w Marly, „Polska Misja Katolicka w Szwajcarii. Wiadomości”, nr 453 (czerwiec) 2009, s. 15-18.

\section{LUDWIK BRONARSKI IN THE LIGHT OF HIS DIARIES STORED IN THE ARCHIVE OF THE POLISH CATHOLIC MISSION IN MARLY}

\section{Summary}

Ludwik Bronarski's Journals (1890-1975) can be found in the Archives of the Polish Catholic Mission in Marly near Fribourg in Switzerland. Their author spent most of his life in Switzerland. After studying Music History in Vienna (1913), Ludwik began to work on a doctoral thesis devoted to the songs of Hildegard of Bingen in Fribourg in Switzerland. He stayed abroad till the end of his life. L. Bronarski undertook various jobs to earn his living, he also promoted Polish culture and literature. He was an editor in encyclopaedia publisher „La Pologne 1919-1939”. In addition, he cooperated with Publications encyclopédique sur la Pologne. On the initiative of Ignacy Jan Paderewski he prepared a critical edition of the works of Frederic Chopin (ed. 1949-1961).

Due to the outbreak of the war and the family situation, he did not continue further academic work at university. As a scholar Ludwik Bronarski is mostly known thanks to his publications on the works of Fryderyk Chopin (Harmonika Chopina, Études sur Chopin and Chopin en l'Italie). He was a patriot and a pious man. He, together with his brother Alfons, supported the initiative of the foundation of the Polish Catholic Mission, to which they donated the house, family archives and a rich collection of books. The Polish Catholic Mission in Marly, a town located near Fribourg, has existed since 1950.

The preserved Ludwik Bronarski's Journals present the daily life of the family, current events, including the exceptional ones, for example, Henryk Sienkiewicz's funeral and a meeting with I.J. Paderewski.

Keywords: Polish Catholic Mission, Switzerland, Marly, Ludwik Bronarski, Fryderyk Chopin 